\title{
Dental Care for an adolescent with chromosome pentasomy: rare case report with a two year follow-up
}

\author{
Atenção Odontológica a jovem com pentassomia cromossômica: relato de caso raro com \\ acompanhamento de 2 anos
}

\author{
Nayara Silva ALVES 1 \\ Andréa Videira ASSAF ${ }^{1}$ \\ Ângela Maria MARTINS ${ }^{1}$ \\ Marlus Roberto Rodrigues CAJAZEIRA' \\ Leonardo Santos ANTUNES' \\ Flávia Maia SILVEIRA
}

\begin{abstract}
Pentasomy of the $x$ chromosome is a rare syndrome of unknown incidence and there are few reports in the scientific literature, especially in terms of dental care for patients with this syndrome. The aim of this study was to report the dental care given to an adolescent with pentasomy of the $X$ chromosome. The patient presented a cleft palate, impacted teeth, malocclusion, high caries activity, gingivitis and multiple tooth loss due to caries. Despite the difficulties of carrying out the dental work due to involuntary movements and the initial lack of collaboration from the patient the overall dental care was completed on an outpatient basis. The therapeutic success of the treatment was strongly supported by the significant cooperation and relationship that grew up along the period of the treatment, as well as the desire to have the treatment done by both the patient and her parents.
\end{abstract}

Indexing terms: Genetic nondisjunction; Chromosomes; Psychomotor impairment; Oral health

\section{RESUMO}

A pentassomia do cromossomo x é uma síndrome rara, de incidência desconhecida e com poucos relatos na literatura científica, especialmente no que diz respeito à atenção odontológica para pacientes portadores da mesma. O objetivo deste estudo foi relatar um caso de atenção odontológica a uma jovem com pentassomia do cromossomo x, que apresentava fenda palatina, dentes inclusos, má-oclusão, alta atividade de cárie, gengivite e múltiplas perdas dentárias devido à cárie. Apesar das dificuldades de se realizar o tratamento dentário devido aos movimentos involuntários e a não colaboração inicial da paciente, houve total viabilidade da atenção odontológica em âmbito ambulatorial, observandose significativa cooperação, formação de vínculo e adesão ao tratamento pela mesma e seus responsáveis, o que gerou sucesso terapêutico.

Termos de indexação: Não Disjunção Genética; Cromossomos; Deficiência Psicomotora; Saúde bucal

\section{INTRODUCTION}

Pentasomy $X$ is a rare disorder of the sex chromosomes, which only affects females and is characterized by the presence of five chromosomes " $x "(49, x x x x x)$ instead of two $(46, x x)$. The development mechanism of this genetic abnormality is related to the non-disjunction of the genetic material during meiosis, however its true incidence is still unknown ${ }^{1-2}$.

The most common features of this syndrome are delayed psychomotor development with kyphosis, muscular hypotonia, ocular hypertelorism, slanted eyes (epicanthal folds), malformed toes, short neck, thick and flat nose, tooth abnormalities, overlapping toes and clinodactyly. Other signs such as hydrocephalus, microcephaly and/or brachycephaly, high palate, single transverse palmar crease, malformed or low-set, low hairline at the nape and/or pelvis may be present. As with other genetic abnormalities, definite diagnosis is only confirmed via karyotyping ${ }^{1-3}$.

Adopting measures to promote health, as well as early preventive and curative actions is important when providing dental care for patients with special needs. Also the interaction of the patient and family with the professional is essential for the success of the treatment ${ }^{4}$. A lack of understanding between a professional and a

\footnotetext{
${ }^{1}$ Universidade Federal Fluminense, Faculdade de Odontologia, Departamento de Formação Específica. Rua Doutor Silvio Henrique Braune, 22, Centro, 28625-650, Nova Friburgo, RJ, Brasil. Correspondência para / Correspondence to: NS ALVES. E-mail: <nayaraalves@id.uff.br>.
} 
patient and family in terms of the patient's oral health can cause an accumulation of dental needs ${ }^{4-5}$.

This paper aims to report a case of dental care given to an adolescent with pentasomy $X$. The treatment began in 2012 and continued with regular monitoring for two years, in Nova Friburgo, Rio de Janeiro, Brazil.

\section{CASE REPORT}

This study was approved by the Ethics and Research Committee of the University Hospital Antonio Pedro, under CMM/HUAP No 061/09, conducted in accordance with the Declaration of Helsinki and its publication was authorized by those responsible for the 19 year-old melanoderma female patient diagnosed with pentasomy $X$ through the signing of the Informed Consent. The monthly income of the patient's family

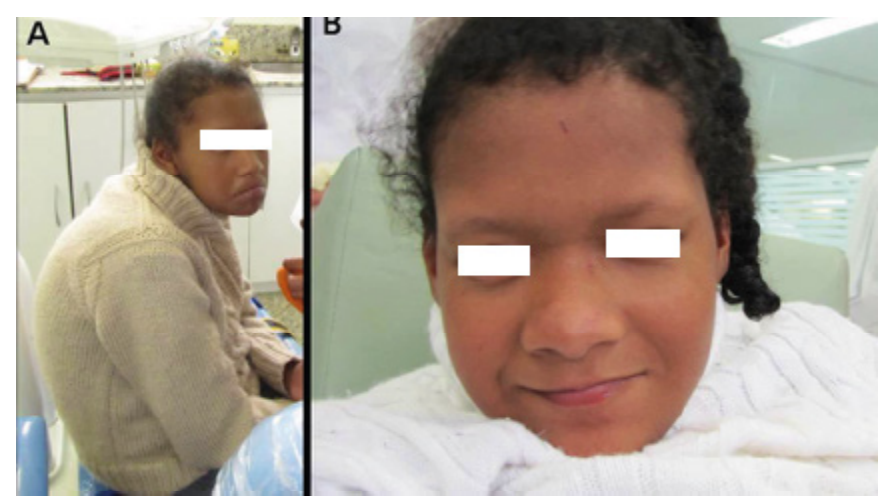

Figure 1. Extraoral photography: A) kyphosis B) Eye Hypertelorism. Nova Friburgo, RJ, Brazil, 2012. was approximately four Brazilian minimum salaries (US\$ $1,298.65)$ and her parents only had an incomplete basic education of three years.

The parents sought the Faculty of Dentistry, at the Federal Fluminense University complaining, of "caries in almost all their daughter's teeth." Her parents reported that due to her health condition many professionals refused to treat her or recommended extraction of all the teeth affected by caries under general anesthesia.

The extra-oral examination of the patient presented ocular hypertelorism with strabismus, intellectual disability, limited mobility, hypotonia and kyphosis (Figure 1A, B).

The intraoral examination detected the presence of several active carious lesions affecting the enamel and dentin, gingivitis, malocclusion and cleft palate. Twelve teeth were missing; these were: 18, 17, 15, 13, 12, 22, 23, 37, 38, 42, 47 and 48 (Figures 2, 3A e 4A).

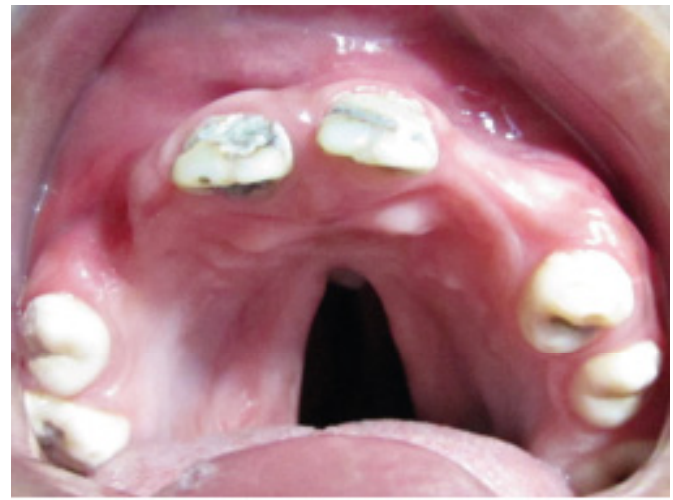

Figure 2. Intraoral Photography: Cleft palate and multiple missing teeth. Nova Friburgo, RJ, Brazil, 2012

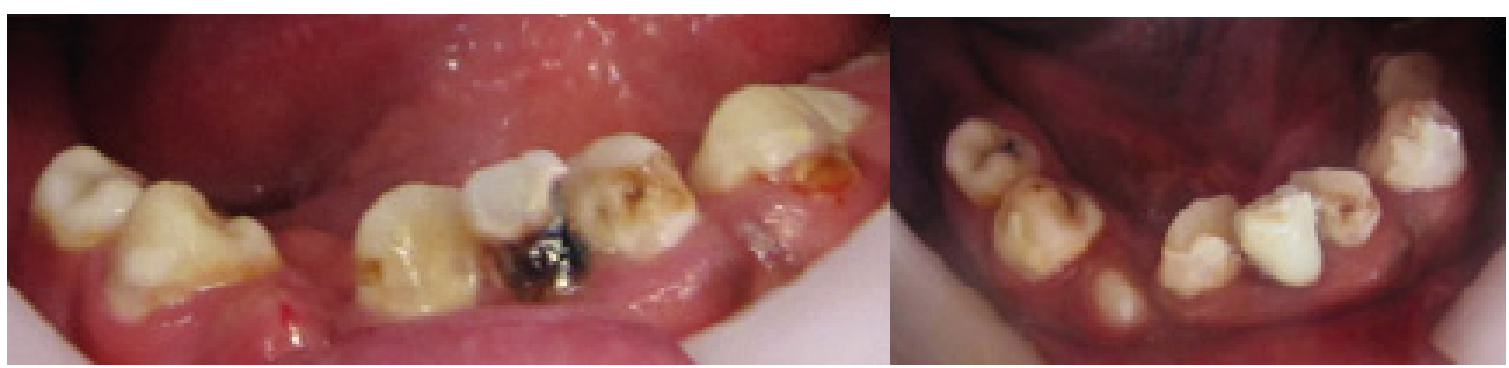

Figure 3. Intraoral Photography lower arch: A) before dental treatment. Nova Friburgo, RJ, Brazil, 2012.B) after dental treatment. Nova Friburgo, RJ, Brazil, 2014.

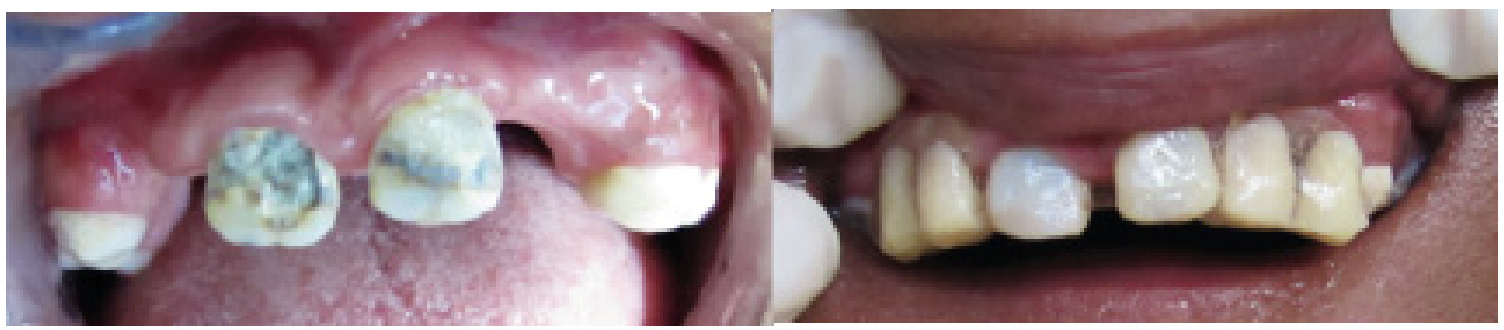

Figure 4. Intraoral Photography arcade higher:A) before the dental rehabilitation. Nova Friburgo, RJ, Brazil, 2012. B) after rehabilitation, with removable occlusive apparatus Nova Friburgo, RJ, Brazil, 2014. 
The dental care involved a multidisciplinary team consisting of graduate students and professors of clinical dentistry, who were able to interact with the patient and her family with verbal reassurance and psychological conditioning that they would provide safe and suitable treatment. Due to the constant involuntary movements that prevented positioning her in the dental chair and in order to make the patient as comfortable as possible the EMAD Godoy ${ }_{\circledast}$ module stabilizer was used. This procedure eliminated the possibility of consequently hospitalization and psychological trauma for the patient and the family (Figure 5).

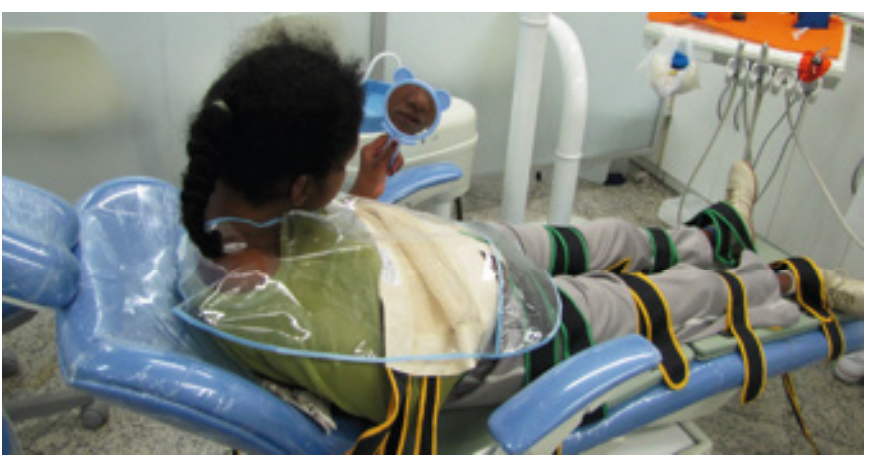

Figure 5. Godoy® Stabilizer/EMAD module. Nova Friburgo, RJ, Brazil, 2014.

Educational health guidance was given to the patient and her caregivers for the control of biofilm through tooth-brushing and flossing (Figure 6). In addition, the patient's diet was evaluated and explanations concerning fermentable carbohydrates as a factor for dental caries were given along the period of treatment, which consisted of 15 sessions of approximately 2 hours each.

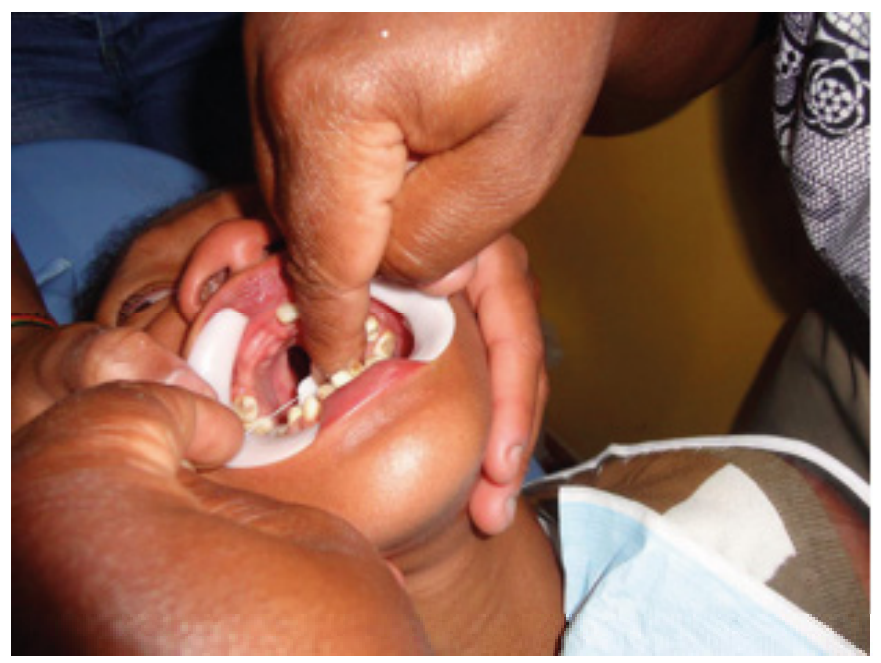

Figure 6. oral hygiene practice carried out by the mother. Nova Friburgo, RJ Brazil, 2014

The initial phase of the treatment was to stabilize the oral environment and control tooth decay using: dental prophylaxis with prophylaxis paste with a Robinson brush and rubber cup; weekly applications of fluoride varnish on all teeth with caries activity. Also, the interim therapeutic restorations (ITR) was carried out to remove carious dentin with dentin excavators and the restoration of cavities was performed with conventional ionomer glass cement (Maxxion $\mathrm{R}^{\circledR}$ ). The ITR approach was applied to the elements $14,24,31,32,33,34,41,42,44$. Only element 16 was extracted due to the extensive decay caused by caries (Figure 3B).

After stabilizing the oral environment, direct restorations with composite resin were carried out on the following elements $17,14,11,21,25$. Then a removable occlusive apparatus was made for the rehabilitation of the missing teeth and closing of cleft palate (Figure 4B).

Due to involuntary movements of the patient was not an image with good resolution for publication in the case.

After completing the restorative treatment, the patient began a maintenance program with periodic control of biofilm and the use of acidulated fluoride gel $1.23 \%$ and fluoride varnish every 6 months.

The patient has now been followed up for 2 years without any complaints of pain and no eating difficulties by the patient. The satisfaction with the buccal health care is also represented by her mother, even after a year of finishing treatment, as seen by a few lines: "The treatment was very good, excellent service, did not require general anesthesia, I was delighted"; "It was very good, interact with the professionals who attended; With the team, it was great, I felt like I was in my house"; "It was all very good, I was very well treated". Although the health promoting approach was carried out correctly, with effective control of the disease at the early follow-up stages, a reoccurrence of caries in some teeth was observed over time.

\section{DISCUSSION}

Pentasomy $X$ is a rare syndrome of unknown incidence. Limited data are available on the pentasomy $X$ chromosome in the scientific literature. According to Arbelaez et al. until $2010^{6}$ less than 30 cases had been reported in the literature, reflecting the rare nature of this genetic disorder. As regards the oral health status of these patients, with an emphasis on dental care, information is totally lacking.

Generally, the most common signs of this syndrome are psychomotor impairment with kyphosis ${ }^{1}$, hipotonia, ocular hypertelorism², dental abnormalities, high palate and bad occlusion ${ }^{6}$. In this report, the patient 
had psychomotor impairment with limited mobility, opisthotonos posture and ocular hypertelorism, cleft palate, impacted teeth, gingivitis and a high amount of tooth decay linked to a past history of the loss of several teeth. These clinical findings, added to the historical account given by the patient's caretakers, indicate the difficulty of accessing some form of dental care. This lack of access to dental health care corroborates with Cumella et al. ${ }^{4}$, Casamassimo et al. ${ }^{5}$, Gordon et al. ${ }^{7}$, AL-Shehri ${ }^{8}$, who all made similar observations concerning people with special needs who tried to obtain care at outpatient clinics.

The disadvantages of dental patients with special health care needs in a hospital setting under general anesthesia, compared with an outpatient setting under local anesthesia include a greater risk to life due to high doses of depressants of the central nervous system in general anesthesia, authorization restrictions, ineffective in the health-disease process, ie, occasional and purely surgical. The public health system in Brazil is not able to handle the demand and is not properly organized to meet such demands either, especially not for care under general anesthesia?.

Deficiency of dental care for patients with special needs is a national and international issue ${ }^{6,9}$ and questions should be raised to overcome some of these issues, in order to improve the oral health and quality of life of these people. Some factors motivating this problem are considered to be social such as the fear and insecurity of the patient and the professional, lack of professional training to care for such patients, prejudice and poor remuneration, since this kind of treatment for patients with special needs takes more time and requires more physical resources ${ }^{4-5,8-9}$.

However, there have been successful experiences with patients with special needs, as occurs in clinical practice at the School of Dentistry, FOUFF, where outpatient treatment is conducted under local anesthesia for almost all patients with psychomotor impairments ${ }^{10}$.

\section{REFERENCES}

1. Moraes LM, Cardoso LCA, Moura VLS, Moreira MAM, Albert $\mathrm{N}$, Menezes NA, et al. Detailed analysis of $X$ chromosome inactivation in a 49,XXXXX pentasomy. Mol Cytogenet. 2009;2:20. doi: 10.1186/1755-8166-2-20

2. Schoubben E, Decaestecker K, Quaegebeur K, Danneels L, Mortier G, Cornette L. Tetrasomy and pentasomy of the $X$ chromosome. Eur J Pediatr. 2011;170(10):1325-7. doi: 10.1007/ s00431-011-1491-9
As seen in this report there was a reoccurrence of caries despite the periodic maintenance visits. Thus, this clinical observation shows that patients with this type of disability have an increased risk of tooth decay due to the difficulty of controlling caries, due to biofilm and cariogenic diet. Thus, there is a clear need for more frequent and regular monitoring of these patients along with continuous reinforcement of educational and preventive actions for them and their caregivers.

Therefore, based on this account it is clear that, within a philosophy of health promotion, it is possible that these patients can be kept healthy, with the cooperation and communication between the professionals and the family.

\section{CONCLUSION}

This case is unusual in the scientific literature, and the dental work was carried out with great difficulty due to involuntary movements of the patient, the lack of initial collaboration and the fact that it was an almost unknown case in dentistry. However, the full dental care was carried out on an outpatient basis, and was conducted by graduate students, supervised by a team of teachers. There was, after a difficult start, significant collaboration, and a will from the patient and her caretakers to have the treatment, which led to the therapeutic success.

\section{Collaborators}

NS ALVES, LS ANTUNES and FM SILVEIRA were responsible for the care of the patient, additional tests, the manuscript writing. AV ASSAF was responsible for patient care, writing and reviewing the manuscript. ÂM MARTINS and MRR Cajazeira participated in the patient's care and writing of the manuscript.

3. Aytac PC, Tarim E, Sahin FI. Transient hydrops fetalis in a prenatally diagnosed pentasomy X?. J Obstet Gynaecol Res. 2012;38(11):1335-8. doi: 10.1111/j.1447-0756.2012.01868.x

4. Cumella S, Ransford N, Lyons J, Burnham H. Needs for oral care among people with intellectual disability not in contact with Community Dental Services. J Intellect Disabil Res. 2000;44(Pt 1):45-52. doi: 10.1046/j.1365-2788.2000.00252.x

5. Casamassimo PS, Seale NS, Ruehs K. General Dentists' Perceptions of Educational and Treatment Issues Affecting Access to Care for Children with Special Health Care Needs. J Dent Educ. 2004;68(1):23-8. 
6. Arbelaez MHE, Aldana CTS, Bravo NCC, Ospina SY, Mendoza DJF. Análisis clínico y molecular de una paciente con pentasomia del cromosoma X. Acta Biol Colomb. 2010;15(2):61-72.

7. Gordon SM. Dionne RA. Snyde J. Dental fear and anxiety as a barrier to accessing oral health care among patients with special health care needs. Spec Care Dentist. 1998;18(2):88-92.

8. AL-Shehri SAM. Access to dental care for persons with disabilities in Saudi Arabia (Caregivers' perspective). J Disab Oral Health. 2012;13(2):51-61.

9. Silveira FM, Ribeiro AA, Catro GFBA. Tratamento odontológico de crianças com necessidades especiais. In: Duque C, CaldoTeixeira AS, Ribeiro AA, Ammari MM, Abreu FV, Antunes LAA. Odontopediatria: uma visão contemporânea. São Paulo: Santos; 2013. p. 633-644.
10. Stiefel DJ (2002) Dental Care Considerations for Disabled Adults. Spec Care Dentist. 22(3), 26S-39S

Received on: 16/7/2015

Final version resubmitted on: 14/8/2015

Approved on: 8/9/2015 